\title{
The Emulsion Polymerization of Each of Vinyl Acetate and Butyl Acrylate Monomers Using bis (2-ethylhexyl) Maleate for Improving the Physicomechanical Properties of Paints and Adhesive Films
}

\author{
K. A. Shaffei, ${ }^{1}$ A. B. Moustafa, ${ }^{2}$ and A. I. Hamed ${ }^{3}$ \\ ${ }^{1}$ Department of Chemistry, Faculty of Science, Helwan University, Ain Helwan, Helwan 11795, Egypt \\ ${ }^{2}$ Department of Polymers and Pigments, National Research Centre, Elagouza, Cairo 12411, Egypt \\ ${ }^{3}$ BBC Industrial Chemicals Co. Ltd, Accra, Ghana
}

Correspondence should be addressed to K. A. Shaffei, khaled.shaffei2006@yahoo.com

Received 18 December 2008; Revised 19 April 2009; Accepted 8 June 2009

Recommended by Jose Ramon Leiza

Improving the water sensitivity of polyvinyl acetate PVAc films as well as pressure sensitivity, adhesion and washability of polybutyl acrylate were achieved by using bis (2-ethylhexyl) maleate (BEHM). The emulsion polymerization kinetics of vinyl acetate and butyl acrylate in presence of BEHM was studied. The order of the polymerization reaction with respect to the BEHM in presence of each of vinyl acetate and butyl acrylate was studied. The physicomechanical properties of the polyvinyl acetate films and vinyl acetate-butyl acrylate copolymer films were studied in presence of BEHM and the obtained results were matched with those prepared in the presence of pluronic F 108 and showed superior values. The obtained mean average molecular weights were found to be smaller in presence of BEHM assuring the presence of chain transfer reaction.

Copyright $\odot 2009$ K. A. Shaffei et al. This is an open access article distributed under the Creative Commons Attribution License, which permits unrestricted use, distribution, and reproduction in any medium, provided the original work is properly cited.

\section{Introduction}

Surfactants are essential ingredients in emulsion polymerization. They are very important for particle nucleation, stabilization, and shelf life of the latex. However, their presence can also have adverse effects. When latexes are used as film-forming polymers, the adsorbed surfactant can migrate towards the interfaces, creating a separate phase [1-4] that reduces gloss as well as adhesion, and can be entrapped in pockets $[1,5]$ which increase percolation by water, and in general, water sensitivity and adhesion are also affected. Those factors are major drawbacks in applications of paints and other protective coatings [6].

A promising solution to these problems is to covalently link the surfactants to the polymer so that it cannot desorb and migrate during film formation. This is the reason why we use polymerizable surfactants $[3,4,7]$ (surfmers) that impart substantial benefits to film-forming lattices, such as better mechanical properties [8] higher electrolyte stability $[9,10]$. In 1958 the synthesis of the first surfactant monomers was reported [11]. It was found that allyl surfmers decrease the polymerization rate of the main monomer. Lately maleic acid derivatives have been proposed as reactive species since this kind of function can undergo copolymerization with suitable comonomers, but cannot be homopolymerised. The use of surfmers in emulsion polymerization is mainly anionic [12-15] and non-ionic [16] but very little work has been done with cationic and zwitterionic $[17,18]$. In a large collaborative research programme [19] the most appropriate polymerizable function not capable of homopolymerizing in aqueous phase are probably the best to be used as surfmers (e.g., maleates).

Schipper et al. [20] have done some work on the reactive surfmers in heterophase polymerization for high performance polymers, Guyot et al. [21] worked on synthesis of functionalized poly(ethylene oxide)-poly(butylene oxide) copolymer as surfmers, inisurfs and transurfs in heterophase polymerization. They also worked on reactive surfactants in heterophase polymerization. 
In this work we intend to use a new maleate as a comonomer to improve water sensitivity, shear strength of PVAc films as well as the adhesion of PBuA-PVAc copolymer films, studying the kinetics of butyl acyrylate $\mathrm{BuA}$ and vinyl acetate polymers using this bis (2-ethylhexyl) maleate (BEHM) as a comonomer.

\section{Experimental}

Vinyl acetate (VAc) monomer (stabilized with $14 \mathrm{ppm}$ hydroquinone) was provided by $\mathrm{BDH}$. Butyl acrylate (BuA) monomer (stabilized with 14 ppm hydroquinone) was provided by Merck-Schuchart, Germany. Both VAc and BuA were redistilled before use and stored at $-20^{\circ} \mathrm{C}$. Potassium persulfate (KPS) supplied by Labmerk chemicals (India) was recrystallized from water by methanol and the final crystals were vacuum-dried. Sodium bisulphite LR provided by S.D.S fine chemicals. Potassium hydroxide, acetone, methanol and hydroquinone were products of El-Nasr Pharmaceutical Chemical Company (Adwic), Egypt, Bis (2-ethylhexyl) maleate $\mathrm{CH}_{3}\left(\mathrm{CH}_{2}\right)_{3} \mathrm{CH}\left(\mathrm{C}_{2} \mathrm{H}_{5}\right) \mathrm{CH}_{2} \mathrm{O}_{2} \mathrm{CCH}=\mathrm{CHCO}_{2} \mathrm{CH}_{2} \mathrm{CH}\left(\mathrm{C}_{2} \mathrm{H}_{5}\right)$ $\left(\mathrm{CH}_{2}\right)_{3} \mathrm{CH}_{3}$ was from Sigma-Aldrich, Germany; all water used was purified by distillation.

Poly(ethylene glycol) 2,4,6-tris(1-phenyl ethyl)phenyl ether methacrylate (PEGTPMA) copolymerizable monomer $\mathrm{CH}_{2}=\mathrm{C}\left(\mathrm{CH}_{3}\right) \mathrm{CO}_{2}\left(\mathrm{CH}_{2} \mathrm{CH}_{2} \mathrm{O}\right)_{n} \mathrm{C}_{6} \mathrm{H}_{2}\left[\mathrm{CH}\left(\mathrm{CH}_{3}\right) \mathrm{C}_{6} \mathrm{H}_{5}\right]_{3}$ Provided by Sigma, Aldrish Germany.

Acetone sodium bisulfite (ASBS) adducts were prepared by the addition reaction of sodium bisulfite on the carbonyl group of acetone.

\section{The Polymerization Technique}

3.1. Homopolymerization of Either Vinyl Acetate or Butyl Acrylate by Batch Technique. The following ingredients were mixed in a $250 \mathrm{~mL}$ three necked flask, the order of addition was as follows: water, emulsifier, initiator and either VAc or BuA monomer. The polymerization reactions were carried out at $70^{\circ} \mathrm{C}\left( \pm 1^{\circ} \mathrm{C}\right)$ in an automatically controlled water bath (as mentioned previously [22-24]). All the experiments were run with mechanical stirring at $500 \mathrm{rpm}$.

3.2. Sampling. In order to determine the conversion percent during the polymerization, it is necessary to withdraw the samples at various time intervals from the reaction mixture. These samples are relatively small so that the overall composition in the reaction mixture is not seriously affected. Once a sample was removed and put on a preweighed watch glass the reaction was short stopped with 7 ppm hydroquinone and the contents of the watch glass were evaporated at room temperature and then dried in an electric oven till constant weight. Since the composition of the materials in the reaction vessel at the sampling time is known, the conversion percent is easily calculated gravimetrically.

\begin{tabular}{lcc}
\multicolumn{3}{c}{ TaBle 1} \\
\hline Ingredients & Amount $(\mathrm{gms})$ & Concentration mol/L \\
\hline VAc and/or BuA & 50 & $9.43 / 6.98$ \\
BEHM & $0.5,1,1.5$ & \\
KPS/ASBS & $0.168 / 0.2025$ & {$\left[6.25 \times 10^{-3}\right] /\left[12.5 \times 10^{-3}\right]$} \\
Distilled water & 50 & \\
\hline
\end{tabular}

3.3. Semicontineous (Homo and Co Polymerization of Vinyl Acetate and Butyl Acrylate). The semicontineous polymerization method were used to prepare PVAc and/or PBuA of $50 \%$ solid content. The recipes of the polymerization are shown in Table 1.

In this process the amount of emulsifier (pluronic F108) was dissolved in distilled water and charged into the $250 \mathrm{~mL}$ three necked flask. The vinyl acetate and the butyl acrylate monomers were homopolymerized and copolymerized by semicontineous process using the redox initiation system potassium persulphate/Acetone sodium bisulphate KPS/ASBS. The monomer vinyl acetate as well as the butyl acrylate were afterwards independently added dropwisely using two separating funnels at a rate of about $(15 \mathrm{~mL} / \mathrm{hr})$. The polymerization reaction was carried out at $70^{\circ} \mathrm{C}$ for 2 hours using an automatic stirring at $500 \mathrm{rpm}$. The prepared PVAc lattices of high solid content was used in both adhesion and emulsion paint studies.

3.4. Washability Test for Paint Samples of Prepared Lattices Compared with a Commercial Type. Apply the paint sample to be tested on clean glass panels or other specific substrate (PP sheet) of suitable dimensions. Let it to dry for one week before doing the washability test. Measure the dry film thickness of the test film with $r$ film thickness tester. Put the painted panel into the wet abrasion scrub tester 903/2 (washability tester) and apply the test according to (ASTM D2486) [25].

3.5. Latex Paint Preparation. Emulsion paint could be made by using a dispersing mixer machine which is a product of (WILHELM NIEMANN Gmbh \& Co. Germany). The ingredients of the PVAc emulsion paints are shown in Table 2.

\section{Adhesion Measurement}

4.1. Preparation of Glass Panels (ASTM.D 3891-80). The glass plates dimension of $(10 \times 20 \times 0.4) \mathrm{cm}$ must be flat, regular and without any defect on their surface. The glass panels must be cleaned from oil and fats by immersion in petroleum ether then washed by soap and water. The glass panels are finally washed using alcohol and left to dry.

4.2. CROSS Hatch Adhesion. A latex pattern with eleven cuts in each direction is made in the film; to the substrate, a pressure-sensitive tape is applied over the film and then removed, adhesion is evaluated by comparison with 
TABLE 2

\begin{tabular}{lll}
\hline 1. & Dispersing medium (water) & $60 \mathrm{gms}$ \\
2. & Pigment (titanium dioxide, Tiona 595 millennium) & $25 \mathrm{gms}$ \\
3. & Filler (calcium carbonate, EJSF Omya Egypt) & $25 \mathrm{gms}$ \\
4. & Binders (PVAc) & $50 \mathrm{gms}$ \\
5. & Dispersing agent (Dispex N40) & $2.2 \mathrm{gms}$ \\
6. & Antifoam (fomaster dnh1) & $0.5 \mathrm{gms}$ \\
7. & Ph adjuster (ammonium hydroxide solution 25\%) ms & $0.5 \mathrm{gms}$ \\
8. & Thickening agent (polyacrylics, Viscalex HV30 and Rheovis 152)Ciba & $0.4 \mathrm{gms}$ \\
\hline
\end{tabular}

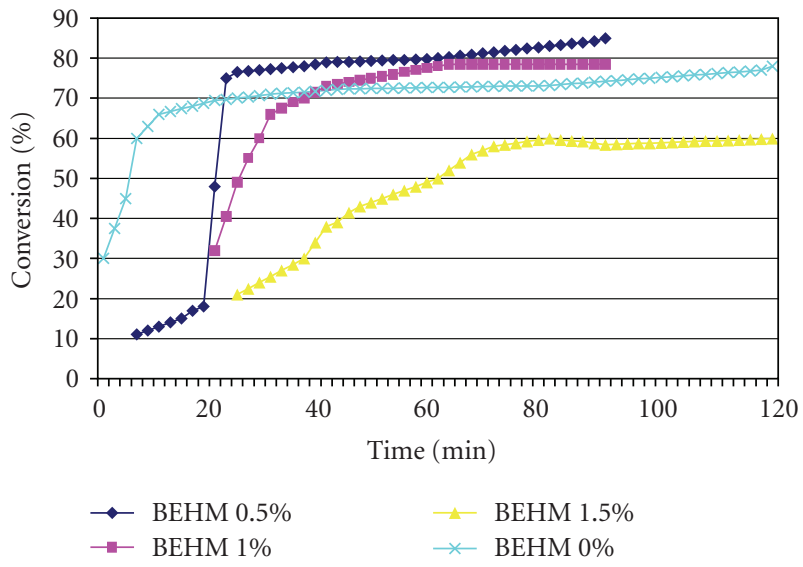

Figure 1: Conversion time curves of Polyvinyl acetate using different concentration of BEHM 0.5, 1, $1.5 \mathrm{gm}$ using redox initiator KPS/ASBS $\left[6.25 \times 10^{-3}\right] /\left[12.5 \times 10^{-3}\right] \mathrm{mol} / \mathrm{L}$ temp $70^{\circ} \mathrm{C} \mathrm{VAc}$ monomer $1.1 \mathrm{gmmol} / \mathrm{L}$.

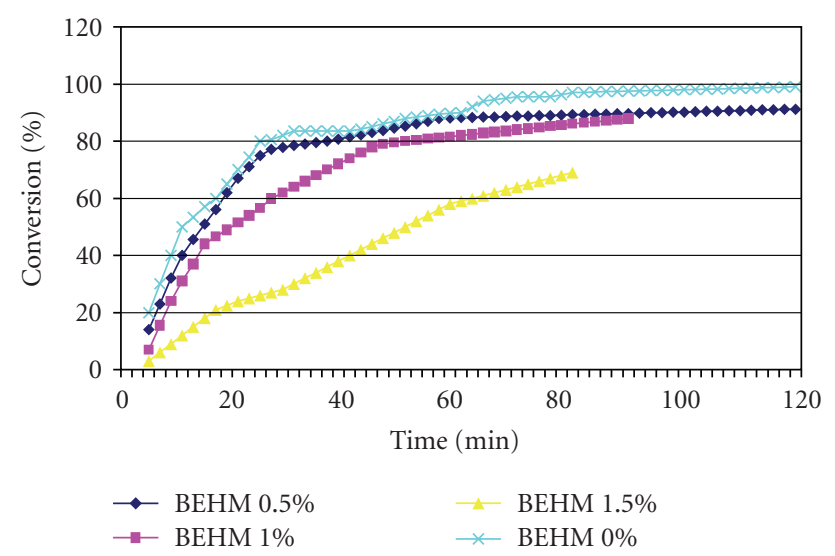

Figure 2: Conversion time curves of Polybutyl acrylate using different concentration of BEHM 0.5, 1, 1.5 gm using redox initiator KPS/ASBS $\left[6.25 \times 10^{-3}\right] /\left[12.5 \times 10^{-3}\right] \mathrm{mol} / \mathrm{L}$ temp $70^{\circ} \mathrm{C} \mathrm{BuA}$ monomer $0.7 \mathrm{gmmol} / \mathrm{L}$.

descriptions and illustrations according to (ASTM, D335995a) Figure 1.

\section{Molecular Weight Measurement}

Molecular weight ( $\mathrm{Mn}$ and $\mathrm{Mw}$ ) of the polymer samples were determined by gel permeation chromatography using

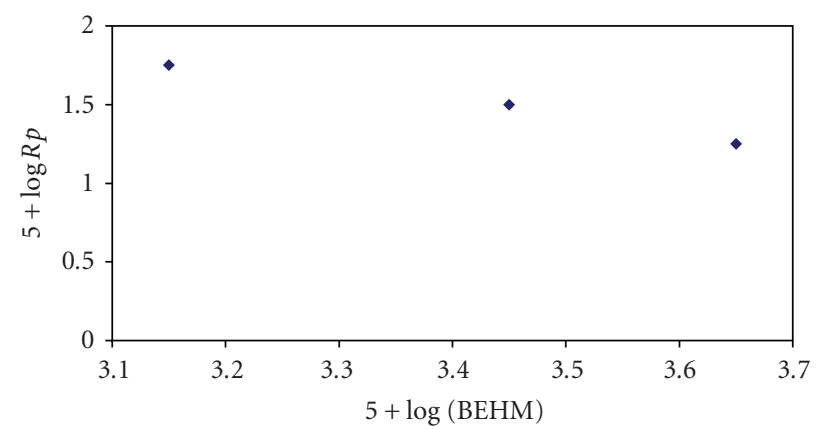

FIGURE 3: Determination of BEHM power redox initiator KPS/ASBS $\left[6.25 \times 10^{-3}\right] /\left[12.5 \times 10^{-3}\right] \mathrm{mol} / \mathrm{L}$ temp $70^{\circ} \mathrm{C} \mathrm{Vac}$ monomer $1.1 \mathrm{gmmol} / \mathrm{L}$.

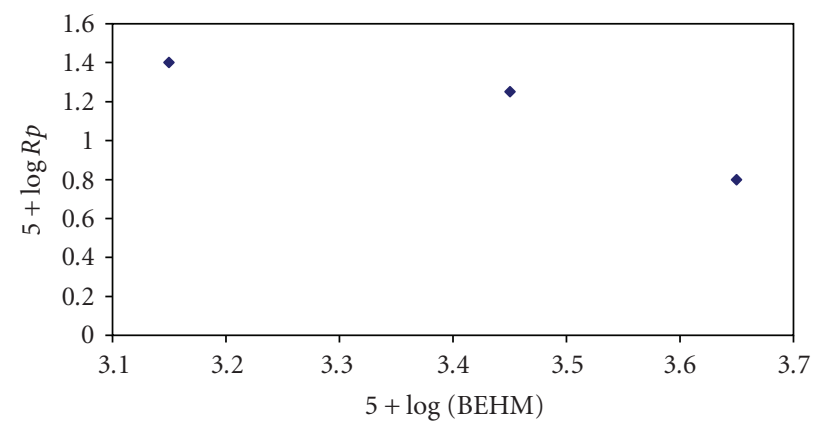

FIGURE 4: Determination of BEHM power redox initiator $\mathrm{KPS} / \mathrm{ASBS}\left[6.25 \times 10^{-3}\right] /\left[12.5 \times 10^{-3}\right] \mathrm{mol} / \mathrm{L}$ temp $70^{\circ} \mathrm{C} \mathrm{BuA}$ monomer $0.7 \mathrm{gmmol} / \mathrm{L}$.

Agilent-1100 GPC-Agilent technologies-Germany. The refractive index detector was G-1362A with $100-104-105$ $\mathrm{A}^{\circ}$ ultra styragel columns connected in series, the solvent used is THF

\section{Results and Discussion}

6.1. Kinetic Study of Emulsion Polymerization of VAc and BuA Monomers Using BEHM. Figure 1 shows an accelerated rate of polymerization, Rp of Vinyl acetate using BEHM through a period of 20 minutes reaching about $75 \%$ conversion when using $0.5 \% \mathrm{BEHM}$ of the concentration. After this period of time, the reaction rate decreased due to the consumption of $75 \%$ of the monomer. 
TABLE 3: Comparison of shear strength between adhesive lattices formulation with different types of surfactants and surfmers.

\begin{tabular}{lllll}
\hline & Commercial latex & Prepared latex (PVAc) & Prepared latex (PVAc) & $\begin{array}{l}\text { Prepared latex (PVAc) } \\
\text { Ingredients }\end{array}$ \\
& $\begin{array}{l}\text { EAGL H (480/50) } \\
\text { (50) } 50 \%\end{array}$ & $\begin{array}{l}\text { Susing classical } \\
\text { Surfmer 1 gm }\end{array}$ & $\begin{array}{l}\text { 50\% using ((BEHM)) } \\
\text { surfactant 1 gm } \\
\text { (PLURONIC F108) }\end{array}$ \\
\hline PVAc (homopolymer) & 70 & 70 & 70 & 70 \\
CaCO3 & 18 & 18 & 18 & 18 \\
DIBP & 1 & 1 & 1 & 1 \\
Water & 10 & 10 & 10 & 10 \\
Defamer & 1 & 1 & 1 & 1 \\
Total & 100 & 100 & 100 & 100 \\
Shear strength $\left(\mathrm{Kg} / \mathrm{cm}^{2}\right)$ & 122 & 92 & 120 & 87 \\
\hline
\end{tabular}

TABLE 4: Water resistance of the latex films.

\begin{tabular}{lllll}
\hline & Commercial latex & Prepared latex (PVAc) & Prepared latex (PVAc) & $\begin{array}{l}\text { Prepared latex(PVAc) } \\
\text { Type of latex }\end{array}$ \\
& $\begin{array}{l}\text { EAGL H (480/50) } \\
\text { (50) 50\% }\end{array}$ & $\begin{array}{l}\text { 50\% using (PEGTPA) } \\
\text { Surfmer 1 gm }\end{array}$ & $\begin{array}{l}\text { 50\% using ((BEHM)) } \\
1 \text { gm }\end{array}$ & $\begin{array}{l}\text { surfactant 1 gm } \\
\text { (PLURONIC F108) }\end{array}$ \\
\hline Water spot resistance sec. & 10 & 28 & 45 & 8 \\
\hline
\end{tabular}

Using higher concentration of BEHM 1\%, 1.5\% resulted into lower conversion percentage of monomer under the same reaction conditions, this could be explained through the following: Increasing the BEHM percentage decreases the rate of polymerization and this could be due to mass transfer limitations for radical entry created by hairy layers formed by nonionic comonomer [26, 27]. This could also be due to the less mobility of BEHM molecules and results in less Brownian movement, and from Table 6 the molecular weights show low values assuring a chain transfer reaction.

The same observation was found in case of polymerizing butyl acrylate using the same percentages of the BEHM $0.5 \%$, $1 \%$, and $1.5 \%$ and the data is represented in Figure 2.

The same explanations could be taken into consideration.

Figure 3 represents log Rp versus log BEHM concentration in case of vinyl acetate polymerization; this resulted in the order of reaction -1.3 .

Figure 4 represents log Rp versus log BEHM concentration in case of butyl acrylate polymerization; this resulted in order of reaction -1 .

Both Figures 3 and 4 show the same behavior of the BEHM with respect to decreasing the same rate of polymerization when higher percentages of it are used. [28].

This phenomena was also found by Klimenkovs et al.

6.2. The Effect of BEHM on the Application of Poly (Vinyl Acetate) and Poly (Butyl Acrylate) Lattices.

6.2.1. The Shear Strength of Poly (Vinyl Acetate) 50\% Solid Content Using BEHM in Comparison with Different Types of Surfactants. The shear strength of PVAc homopolymer $50 \%$ solid content prepared in presence of $1 \mathrm{gm}$ BEHM was measured and compared with using $1 \mathrm{gm}$ of other surfmers for the same polymer under the same conditions of application and we obtained the results given in Table 3. These results indicate that the shear strength when using BEHM is higher than that obtained by using PLURONIC F108 and PEGTPMA but found to be very near to the shear strength value obtained by using the commercial sample EAGLE H (480/50).

6.2.2. The Water Resistance of Poly (Vinyl Acetate) Latex 50\% in the Presence of BEHM as a Comonomer in Comparison with Other Surfactants. The Water resistance of poly(vinyl acetate) latex 50\% solid content prepared using 1 gm BEHM was examined (and given in Table 4 ) then compared with the water resistance of poly(vinyl acetate) $50 \%$ solid content prepared using $1 \mathrm{gm}$ classical surfactant PLURONIC F108; and with poly(vinyl acetate) latex $50 \%$ solid content prepared using $1 \mathrm{gm}$ PEGTPMA and the data was compared with that of the commercial latex EAGL H (480/50) (50) (50\%). A superior water resistance for PVAc prepared using BEHM was obtained over all the other types of PVAc prepared either by using the classical surfactant PLURONIC F108 or PEGTPMA surfmer or even the commercial latex EAGL $H$. This superior water resistance could be due to the presence of the maleate group in the BEHM monomer which gives the poly(vinyl acetate) this superior water resistance as it is known that the BEHM molecule is attached to the main backbone structure of the poly(vinyl acetate) as a copolymer in our case.

6.2.3. Comparison of Adhesion, Washability and Hardness for (VAc/BuAc) Co-polymer Prepared Using BEHM and a Classical Surfactant. Table 5 shows the adhesion, hardness and washability for (PVAc/BuAc) 35 : 15 co-polymer, 50\% solid content prepared using $1 \mathrm{gm}$ BEHM in comparison with PVAc/BuA 35 : 15 co-polymer, 50\% solid content using classical surfactant $1 \mathrm{gm}$ PLURONIC F108; it is clear 
TABLE 5: The properties of paint produced from emulsion lattices.

\begin{tabular}{lll}
\hline Type of emulsion Paint character & $\begin{array}{l}\text { Prepared latex (VAc/BuA) co-polymer } \\
(35: 15) \text { emulsion paint 50\% using } \\
(\text { BEHM) } 1 \text { gm }\end{array}$ & $\begin{array}{l}\text { Prepared latex (VAc/BuA) co-polymer } \\
(35: 15) \text { emulsion paint 50\% using } \\
\text { classical surfactant 1 gm (PLURONIC } \\
\text { (F108) }\end{array}$ \\
\hline Drying time (min) & 6 & 5 \\
Adhesion (135) & $2 \mathrm{~B}$ & $0 \mathrm{~B}$ \\
Hardness (sec.) & 72 & 68 \\
Thickness $(\mu)$ & 40 & 30 \\
Washability $($ cycle) & 62 & 28 \\
\hline
\end{tabular}

TABle 6: Obtained the molecular weights M.wt of different PVAc,P(VAc BuA) (35/15)and their copolymers at different Surfactant and Surfmers.

\begin{tabular}{lccc}
\hline Prepared latex & Surfmer $\backslash$ Surfactant & $\mathrm{Mn} \times 10^{5}(\mathrm{gm} / \mathrm{mol})$ & $\mathrm{Mw} \times 10^{5}(\mathrm{gm} / \mathrm{mol})$ \\
\hline \multirow{2}{*}{ PVAc } & BEHM 1 gm & 1.56 & 8.22 \\
& PEGTPMA 1 gm & 3.62 & 9.38 \\
& Pluronic F108 1 gm & 3.35 & 8.66 \\
\hline \multirow{2}{*}{ VAc/BuA (35: 15) } & BEHM & 2.14 & 6.67 \\
& Pluronic F108 1 gm & 4.86 & 9.93 \\
\hline
\end{tabular}

from this table a superior washability and adhesion for (PVAc/BuAc) prepared using BEHM than (PVAc/BuAc) prepared using classical surfactant (PLURONIC F108). The presence of maleate group in this copolymer could be the dominant factor causing these results.

6.2.4. Effect of Polymer Molecular Weight on the Physicomechanical Properties. It is clear from Table 6 that the mean number average molecular weights Mn of PVAc prepared in the presence of BEHM is lower than that obtained in the presence of either PEGTPMA or pluronic F108 inspite of this, the adhesion, the shear strength and the hardness of PVAc latex films using BEHM exceeds those for PVAc latex films using the other surfmers. This could be explained via copolymerization of the BEHM with the PVAc and resulted in improvement of the physicomechanical properties to a greater extent.

\section{Conclusion}

In this manuscript the emulsion polymerization of vinyl acetate and butyl acrylate in presence of bis (2-ethylhexyl) maleate (BEHM) was studied. The order of the polymerization reaction with respect to BEHM was calculated using the two different monomers and found to be 1.3 and 1 for vinyl acetate and butyl acrylate respectively. This added BEHM monomer resulted in superior physicomechanical properties of the produced Poly (vinyl acetate) and its co-polymer with butyl acrylate films even with low molecular weight. The presence of the maleate group with BEHM dramatically increases the water resistance of PVAc films, the washability of $(\mathrm{PVAC} / \mathrm{BuA})$ films and the shear strength of PVAC films.

\section{References}

[1] J. L. Keddie, "Film formation of latex," Materials Science and Engineering R, vol. 21, no. 3, pp. 101-170, 1997.

[2] A.-C. Hellgren, P. Weissenborn, and K. Holmberg, "Surfactants in water-borne paints," Progress in Organic Coatings, vol. 35, no. 1-4, pp. 79-87, 1999.

[3] S. Lam, A. C. Hellgren, M. Sjöberg, et al., "Surfactants in heterophase polymerization: a study of film formation using atomic force microscopy," Journal of Applied Polymer Science, vol. 66, no. 1, pp. 187-198, 1997.

[4] E. Aramendia, M. J. Barandiaran, J. C. de la Cal, J. Grade, T. Blease, and J. M. Asua, "Improving latex performance by using polymerizable surfactants," in Polymer Colloids. Science and Technology of Latex Systems, ACS Symposium Series, 801, p. 168, 2002.

[5] D. Juhué and J. Lang, "Latex film surface morphology studied by atomic force microscopy: effect of a non-ionic surfactant postadded to latex dispersion," Colloids and Surfaces A, vol. 87, no. 3, pp. 177-185, 1994.

[6] B. J. Roulstone, M. C. Wilkinson, and J. Hearn, "Studies on polymer latex films-II: effect of surfactants on the water vapour permeability of polymer latex films," Polymer International, vol. 27, no. 1, pp. 43-50, 1992.

[7] J. M. Asua and H. A. S. Schoonbrood, "Reactive surfactants in heterophase polymerization," Acta Polymerica, vol. 49, no. 12, pp. 671-686, 1998.

[8] B. W. Greene and D. P. Sheetz, "In situ polymerization of surface-active agents on latex particles-II: the mechanical stability of styrene/butadiene latexes," Journal of Colloid and Interface Science, vol. 32, no. 1, pp. 96-105, 1970.

[9] A. Filet, J. Guillot, T. Hamaide, and A. Guyot, "Emulsion copolymerization of styrene with a nonionic styrenicpolymerizable surfactant," Polymers for Advanced Technologies, vol. 6, no. 7, pp. 465-472, 2003.

[10] R. H. Ottewill and R. Satgurunathan, "Nonionic latices in aqueous media-part 4: preparation and characterisation 
of electrosterically stabilised particles," Colloid and Polymer Science, vol. 273, no. 4, pp. 379-386, 1995.

[11] H. H. Freedman, J. P. Mason, and A. I. Medalia, "PolysoapsII: the preparation of vinyl soaps," Journal of Organic Chemistry, vol. 23, no. 1, pp. 76-82, 1958.

[12] K. Yokota, A. Ichihara, and H. Shinke, in Industrial Application of Surfactants, vol. 3, chapter 29, RSC, Lodon, UK, 1992.

[13] M. B. Urquiola, V. L. Dimonie, E. D. Sudol, and M. S. El-Aasser, "Emulsion polymerization of vinyl acetate using a polymerizable surfactant-II: polymerization mechanism," Journal of Polymer Science, Part A, vol. 30, no. 12, pp. 26312644, 1992.

[14] K. Holmberg, "Polymerizable surfactants," Progress in Organic Coatings, vol. 20, no. 3-4, pp. 325-337, 1992.

[15] K. Tauer, K. H. Goebel, S. Kosmella, K. Stähler, and J. Neelsen, Makromol Chem, Macromol Symp., vol. 31, p. 107, 1990.

[16] P. Ferguson, D. C. Sherrington, and A. Gough, "Preparation, characterization and use in emulsion polymerization of acrylated alkyl ethoxylate surface-active monomers," Polymer, vol. 34, no. 15, pp. 3281-3292, 1993.

[17] K. Yamaguchi, S. Watanabe, and S. Nakahama, Macromolecular Chemistry and Physics, vol. 190, p. 195, 1989.

[18] S. Watanaba, H. Ozaki, K. C. Mitsuhashi, S. Nakahama, and K. Yamaguchi, "Emulsion polymerization of styrene using phospholipids with polymerizable chain as an emulsifier," Macromolecular Chemistry and Physics, vol. 193, no. 11, pp. 2781-2792, 1992.

[19] M. J. Unzué, H. A. S. Schoonbrood, J. M. Asua, et al., "Reactive surfactants in heterophase polymerization-VI: synthesis and screening of polymerizable surfactants (surfmers) with varying reactivity in high solids styrene-butyl acrylate-acrylic acid emulsion polymerization," Journal of Applied Polymer Science, vol. 66, no. 9, pp. 1803-1820, 1997.

[20] E. T. W. M. Schipper, O. Sindt, T. Hamaide, et al., "Reactive surfactants in heterophase polymerization for high performance polymers. Part 1. Synthesis of functionalized poly(ethylene oxide)-b-poly(butylene oxide) copolymers as surfmers inisurfs and transurfs in heterophase polymerization," Colloid \& Polymer Science, vol. 276, no. 5, pp. 402-411, 1998.

[21] A. Guyot, K. Tauer, J. M. Asua, et al., "Reactive surfactants in heterophase polymerization," Acta Polymerica, vol. 50, no. 2-3, pp. 57-66, 1999.

[22] A. S. Badran, A. A. Yehia, A. B. Moustafa, and S. M. M. Shendy, Acta Polymerica, vol. 41, p. 187, 1990.

[23] A. S. Badran, A. B. Moustafa, A. A. Yehia, and S. M. M. Shendy, "Emulsion polymerization of vinyl acetate initiated by potassium persulfate-cyclohexanone sodium bisulfite redox pair system," Journal of Polymer Science Part A: Polymer Chemistry, vol. 28, no. 2, pp. 411-424, 1999.

[24] A. S. Badran, A. M. Ramadan, A. B. Moustafa, and K. A. Shaffei, "Effect of some sodium bisulfite adducts of different chain lengths on the course of the emulsion polymerization of vinyl acetate," Journal of Applied Polymer Science, vol. 49, no. 2, pp. 187-196, 1993.

[25] A. S. Dunn and P. A. Taylor, "The polymerization of vinyl acetate in aqueous solution initiated by potassium persulphate at $60^{\circ} \mathrm{C}$," Macromolecular Chemistry and Physics, vol. 83 , no. 1 , pp. 207-219, 1965.

[26] I. Capek, "Sterically and electrosterically stabilized emulsion polymerization. Kinetics and preparation," Advances in Colloid and Interface Science, vol. 99, no. 2, pp. 77-162, 2002.
[27] E. M. Coen, R. A. Lyons, and R. G. Gilbert, "Effects of poly(acrylic acid) electrosteric stabilizer on entry and exit in emulsion polymerization," Macromolecules, vol. 29, no. 15, pp. 5128-5135, 1996.

[28] I. Klimenkovs, I. Zhukovska, I. Uzulina, A. Zicmanis, and A. Guyot, "Maleic diamide polymerizable surfactants. Applications in emulsion polymerization," Comptes Rendus Chimie, vol. 6, no. 11-12, pp. 1295-1304, 2003. 

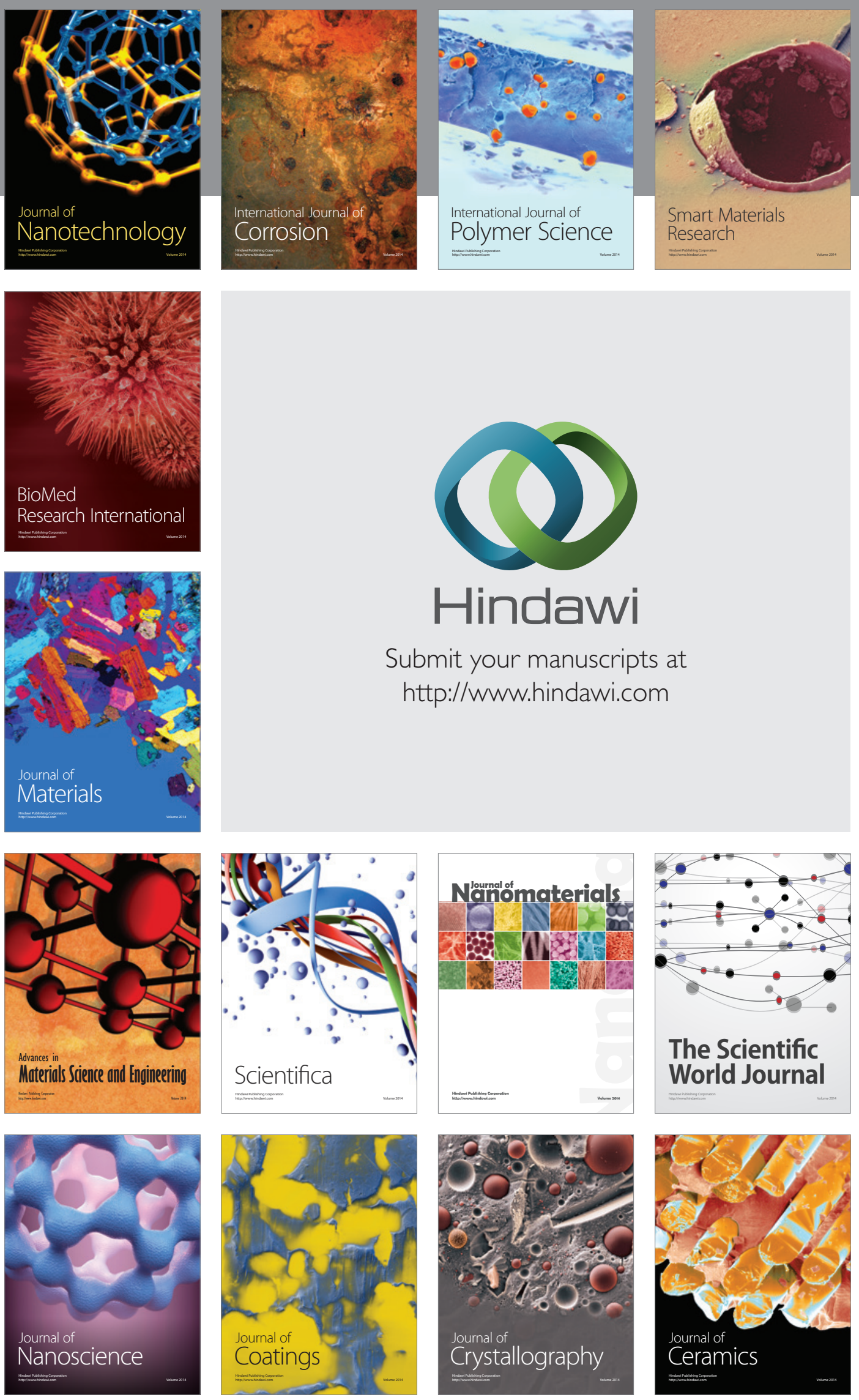

The Scientific World Journal

Submit your manuscripts at

http://www.hindawi.com

\section{World Journal}

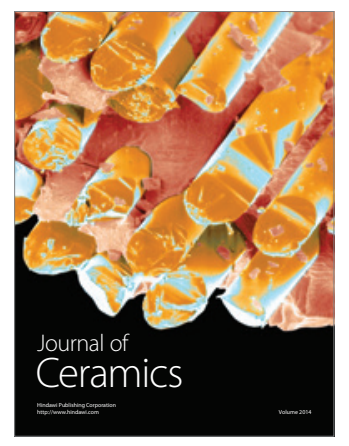

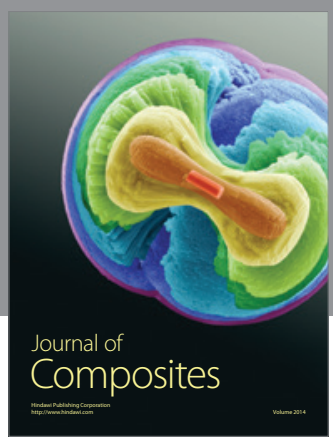
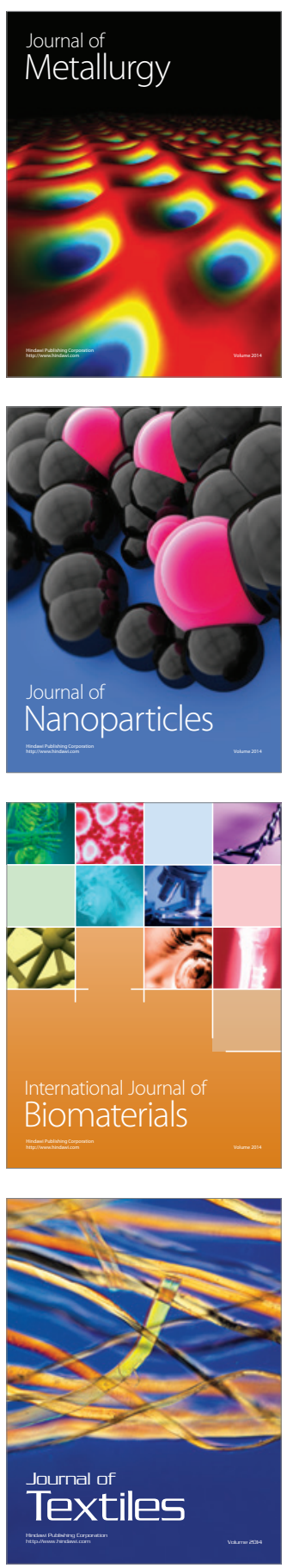